\title{
New and Little Known Species of Loxandrus LeConte 1852 (Coleoptera: Carabidae) from North and South America
}

\author{
Kipling W. Will and James K. Liebherr
}

Department of Entomology, Cornell University, Ithaca, NY, USA

Received: 10 February 1998

Accepted: 28 May 1998

\begin{abstract}
Three new species of beetles in the genus Loxandrus are described: L. straneoi from the southern United States, L. icarus from the Eastern United States, and L. quinarius from central Bolivia. Loxandrus icarus, inhabitant of wet lowland habitat, is unique among eastern North American species in having reduced flight wings. The only other North American species with reduced flight wings, L. omiltemi Allen \& Ball, is known from temperate cloud forest habitat in Mexico. Loxandrus quinarius shares a striking phenetic similarity to some members of the African caelostomine genus Strigomerus Chaudoir, and with L. strigomeroides Straneo. Illustrations of the male genitalia of L. strigomeroides and L. mirei Straneo are presented here to assist in identification of these species. The distributional range of $\mathrm{L}$. strigomeroides is newly noted to extend across the Amazon basin. Loxandrus inferus Allen is placed into synonymy under $\mathrm{L}$. velocipes Casey.
\end{abstract}

KEYWORDS: Carabidae, new species, Loxandrus straneoi, L. icarus, L. quinarius, brachyptery, new synonymy.

\section{INTRODUCTION}

Loxandrini sensu Bousquet and Larochelle (1993) is a formalization of the Loxandrus series of Moore (1965) plus the genera added by Allen and Ball (1979). Casey (1913:380) was the first to suggest that species allied with Loxandrus LeConte might deserve tribal recognition, though he knew only a much more restricted set of taxa. Defensive chemicals (Moore \& Wallbank 1968; Moore 1979) and morphological characters (Allen \& Ball 1979) are the basis for recognition of the group as distinct from Pterostichini (Bousquet \& Larochelle 1993:31; but see Straneo 1991 for counter arguments).

Characteristics used to define Loxandrus are plesiomorphies for the tribe. Therefore, Loxandrus is

Correspondence to: Kipling W. Will, Department of Entomology, Comstock Hall, Cornell University, Ithaca, NY 14853-0901, USA. Fax: +1-607-2550939; e-mail: kww4@ cornell.edu probably paraphyletic relative to one or more of the other genera in the tribe (e.g. Adrimus Bates, Oxycrepis Rieche or Zeodera Sloane). Study of all the supraspecific groups within Loxandrini is required so that a more natural classification may be devised. Presently, species assignable to Loxandrus may be separated from other carabid genera using regional keys as follows: for northern North America, Lindroth (1969), for southern North America and Central America, Allen and Ball (1980), for South America, Straneo (1979), for Australia Moore (1965) and, for New Guinea, Darlington (1962).

The North and Central American Loxandrus species were systematically treated by Allen (1972) and Allen and Ball (1980). Many of the species considered in those works appear to comprise a monophyletic group characterized by lack of a spermatheca, and a greatly developed villous canal (e.g. Figs. 24-25, also Liebherr \& Will, in press). The female reproductive tract of L. straneoi and L. icarus are typical 


\title{
New and Little Known Species of Loxandrus LeConte 1852 (Coleoptera: Carabidae) from North and South America
}

\author{
Kipling W. Will and James K. Liebherr
}

Department of Entomology, Cornell University, Ithaca, NY, USA

Received: 10 February 1998

Accepted: 28 May 1998

\begin{abstract}
Three new species of beetles in the genus Loxandrus are described: L. straneoi from the southern United States, L. icarus from the Eastern United States, and L. quinarius from central Bolivia. Loxandrus icarus, inhabitant of wet lowland habitat, is unique among eastern North American species in having reduced flight wings. The only other North American species with reduced flight wings, L. omiltemi Allen \& Ball, is known from temperate cloud forest habitat in Mexico. Loxandrus quinarius shares a striking phenetic similarity to some members of the African caelostomine genus Strigomerus Chaudoir, and with L. strigomeroides Straneo. Illustrations of the male genitalia of L. strigomeroides and L. mirei Straneo are presented here to assist in identification of these species. The distributional range of $\mathrm{L}$. strigomeroides is newly noted to extend across the Amazon basin. Loxandrus inferus Allen is placed into synonymy under $\mathrm{L}$. velocipes Casey.
\end{abstract}

KEYWORDS: Carabidae, new species, Loxandrus straneoi, L. icarus, L. quinarius, brachyptery, new synonymy.

\section{INTRODUCTION}

Loxandrini sensu Bousquet and Larochelle (1993) is a formalization of the Loxandrus series of Moore (1965) plus the genera added by Allen and Ball (1979). Casey (1913:380) was the first to suggest that species allied with Loxandrus LeConte might deserve tribal recognition, though he knew only a much more restricted set of taxa. Defensive chemicals (Moore \& Wallbank 1968; Moore 1979) and morphological characters (Allen \& Ball 1979) are the basis for recognition of the group as distinct from Pterostichini (Bousquet \& Larochelle 1993:31; but see Straneo 1991 for counter arguments).

Characteristics used to define Loxandrus are plesiomorphies for the tribe. Therefore, Loxandrus is

Correspondence to: Kipling W. Will, Department of Entomology, Comstock Hall, Cornell University, Ithaca, NY 14853-0901, USA. Fax: +1-607-2550939; e-mail: kww4@ cornell.edu probably paraphyletic relative to one or more of the other genera in the tribe (e.g. Adrimus Bates, Oxycrepis Rieche or Zeodera Sloane). Study of all the supraspecific groups within Loxandrini is required so that a more natural classification may be devised. Presently, species assignable to Loxandrus may be separated from other carabid genera using regional keys as follows: for northern North America, Lindroth (1969), for southern North America and Central America, Allen and Ball (1980), for South America, Straneo (1979), for Australia Moore (1965) and, for New Guinea, Darlington (1962).

The North and Central American Loxandrus species were systematically treated by Allen (1972) and Allen and Ball (1980). Many of the species considered in those works appear to comprise a monophyletic group characterized by lack of a spermatheca, and a greatly developed villous canal (e.g. Figs. 24-25, also Liebherr \& Will, in press). The female reproductive tract of L. straneoi and L. icarus are typical 
of this group, though they seem to represent two different lineages based on appended gland position. Many females of the genus remain extremely difficult to separate using external morphology. More than 20 of the names proposed for North American species are based only on single female types. These species were not treated by Allen (1972) nor are they included in his key. Species described herein are based on both male and female specimens. Using Allen's (1972) revision and the original descriptions or direct comparison with specimens of the additional species not covered in his work, L. straneoi and $L$. icarus are recognized as additional specific members of the North American fauna using the criteria defined by Nixon and Wheeler (1990), “...diagnosable by a unique combination of character states in comparable individuals".

Over the past 50 years Stefano Straneo contributed greatly to the knowledge of South American Pterostichini $s . l$; this is especially true of the species of Loxandrini. In his most recent publication on the genus Loxandrus, 55 new species were described (Straneo 1991). In that paper he noted that many species remain to be described, so many that development of a key covering all named species was deemed inappropriate.

Herein we make a small contribution to the body of knowledge on Loxandrus with the description of three new species and the presentation of the male genitalia for two species for which the male was either unknown or the only known male was damaged.

\section{MATERIALS AND METHODS}

External structures were examined using a dissecting stereo-microscope at magnification of $100 \times$ or less. Male genitalia were removed after softening the specimens in near-boiling soapy water, with aedeagus and tegmen then cleared in $10 \% \mathrm{KOH}$. The endophallus was everted using methods detailed by Allen (1972). Females were softened in near boiling soapy water, whole abdomens removed and placed in a ceramic spot plate in $10 \% \mathrm{KOH}$ at either room temperature for 24 hours or in warm $10 \% \mathrm{KOH}$ for 5-10 minutes. Further dissection of the female reproductive tract was then done in a $10 \%$ acetic acid solution. The neutralized abdominal apex plus reproductive tract was then place in a saturated Chlo- razol Black ® dye and methyl cellosolve solution. Drawings were made using an ocular grid. Nomenclature of female reproductive tract structures follows Liebherr \& Will (in press).

Collection abbreviations for material used in this study: CMNH, Carnegie Museum of Natural History, Pittsburgh, PA; CUIC, Cornell University Insect Collection, Cornell University; KWWC, first author's personal collection; MCZ, Museum of Comparative Zoology, Harvard; USNM United States National Museum, Washington D.C.; MUIC, Mississippi State University Insect Collection.

\section{RESULTS}

Loxandrus straneoi, new species

(Figs. 1-4, 15, 17, 18, 20, 21, 24, 26)

HOLOTYPE. ơ, $30^{\circ} 51^{\prime} 23^{\prime \prime} \mathrm{N}-88^{\circ} 44^{\prime} 45^{\prime \prime} \mathrm{W}$, USA, Mississippi, George Co., Rt26 at Pascagoula R., 20:III:1997. Coll. K.Will, CUIC Expedition 1997. Deposited in CUIC; ALLOTYPE. + , $33^{\circ} 17^{\prime} 02^{\prime \prime} \mathrm{N}-$ $88^{\circ} 45^{\prime} 20^{\prime \prime} \mathrm{W}$, USA, Mississippi, Noxubee Co., Noxubee Wild.[life] Ref.[uge], 21:III:1997, Coll. K.Will, CUIC Expedition 1997. Deposited in CUIC: PARATYPES. Mississippi, Noxubee County, Noxubee National Wildlife Refuge, campground area, $33^{\circ} 17^{\prime} 03^{\prime \prime} \mathrm{N}-88^{\circ} 45^{\prime} 20^{\prime \prime} \mathrm{W}, 5$ March 1995 , Davidson, Koenig, Acciavatti, Zanol, of deposited CMNH: $30^{\circ} 51^{\prime} 23^{\prime \prime} \mathrm{N}-88^{\circ} 44^{\prime} 45^{\prime \prime} \mathrm{W}$, USA, Mississippi, George Co., Rt26 at Pascagoula R., 20:III:1997, Coll. K.W.Will, $10^{\star}$ deposited KWWC, $10^{\circ}$ deposited MUIC: $33^{\circ} 16^{\prime} 26^{\prime \prime} \mathrm{N}-88^{\circ} 46^{\prime} 04^{\prime \prime} \mathrm{W}$, USA, Mississippi, Noxubee Co., Noxubee Wild.[life] Ref.[uge], 15:III:1997, Coll. K.Will, Headlamping, 3 o $\delta, 1$ 우 deposited KWWC,1 $\delta$ deposited CUIC; same locality data 16:III:1997, 1 d deposited KWWC; same locality data 17:III:1997, searching leaf litter at night, 1 d deposited MCZ: $33^{\circ} 17^{\prime} 02^{\prime \prime} \mathrm{N}-88^{\circ} 45^{\prime} 20^{\prime \prime} \mathrm{W}$, USA, Mississippi, Noxubee Co., Noxubee Wild.[life] Ref.[uge], 21:III:1997, Coll. K.Will, $1 \delta 1 \%$ deposited CUIC, 1 deposited KWWC.

\section{Diagnosis}

Upper surface black, shiny, iridescent; pronotal border, legs and mouthparts paler, testaceous to rufotestaceous; pronotum convex, hind angles obsolete, lateral margin with narrow bead, $3-12$ shallow scat- 

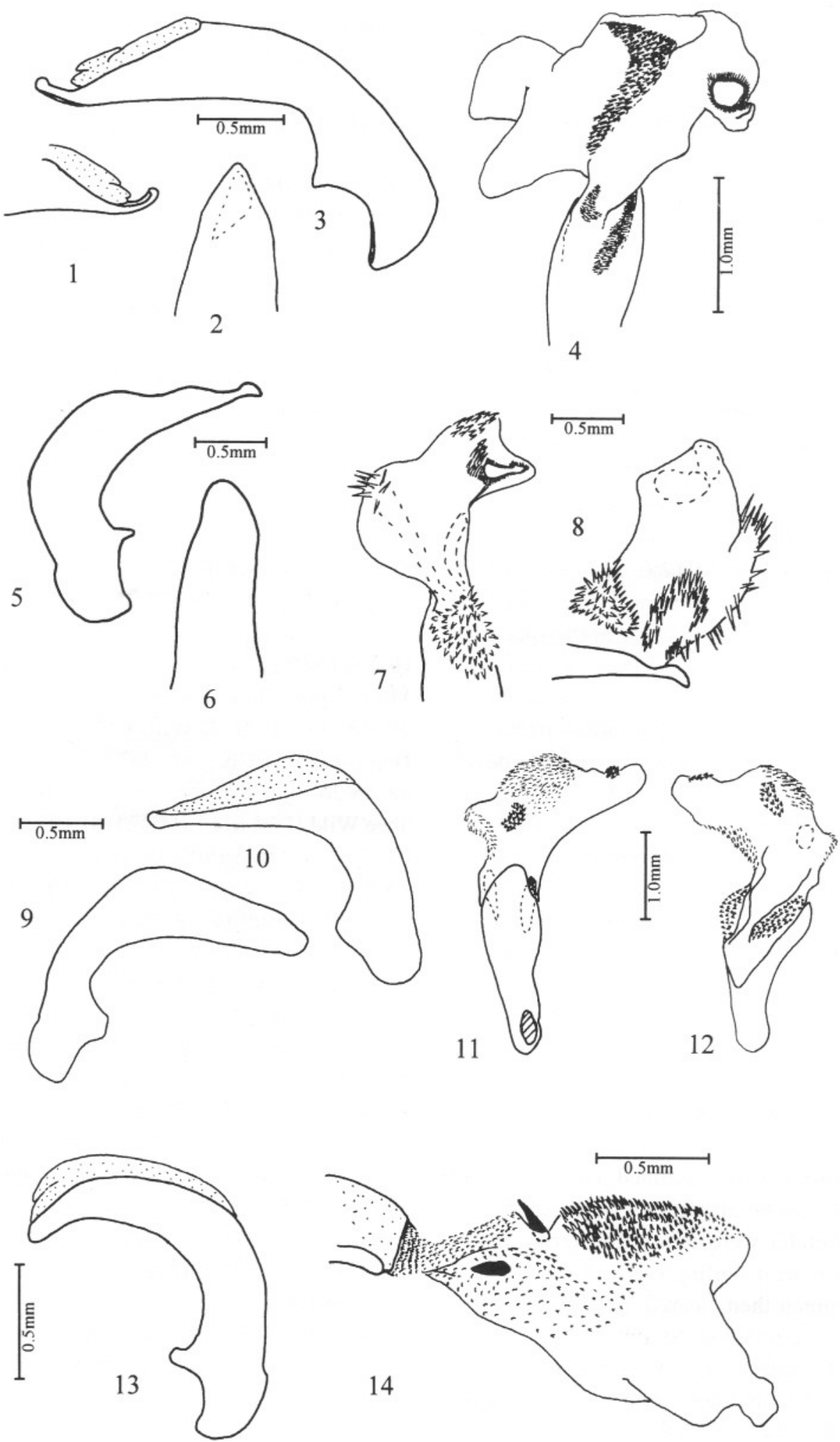

Figs. 1-14. Median lobes. Figs. 1-4. Loxandrus straneoi sp.n. Fig. 1. Right lateral aspect of tip, Fig. 2. Ventral view of tip, Fig. 3. Left lateral aspect, Fig. 4. Endophallus everted, dorsal aspect. Figs. 5-8. L. icarus sp.n. Fig. 5. Right lateral aspect, Fig. 6.Ventral view of tip, Fig. 7. Endophallus everted, dorsal aspect, Fig. 8. Endophallus everted right lateral aspect. Figs. 912. L. strigomeroides. Fig. 9. Left lateral aspect, Fig. 10. Right lateral aspect, Fig. 11. Endophallus everted, ventral aspect, Fig. 12. Endophallus everted, dorsal aspect. Figs. 13-14. L. mirei. Fig. 13. Right lateral aspect, Fig. 14. Endophallus everted, left lateral aspect. 

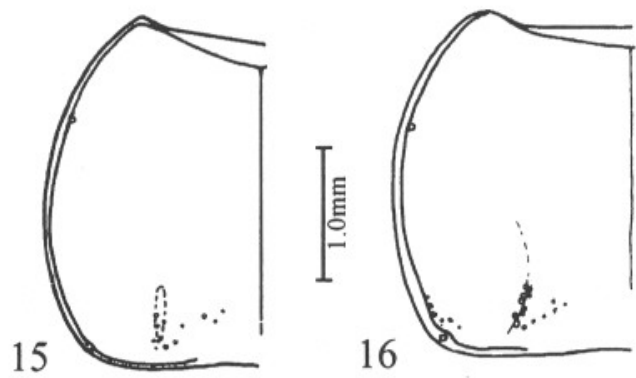

Figs, 15-16. Pronota. Fig. 15. Loxandrus straneoi sp.n. Fig. 16. L. icarus sp.n.

tered punctures basomedially: specimens key to couplet 46 in Allen's (1972) key. They can be separated from specimens of L. agilis (Dejean) and subsequent species in the key by the transversely stretched mesh microsculpture of the metacoxae and the dorsally reflexed tip of the aedeagus (Figs. 1, 3).

\section{Description}

Length from front margin of labrum to elytral apex 8.1-9.0 mm, maximum width across elytra 2.8-3.6 $\mathrm{mm}$; dorsal microsculpture consisting of strongly stretched sculpticells, iridescent, less iridescent on pronotum, obsolete on head; ventral surface duller, microsculpture slightly stretched to nearly isodiametric mesh throughout, weaker medially.

Head short, eyes weakly convex, ocular ratio (width over eyes/width between eyes) 1.5 ; frontal sulci short, faint or obsolete; mandibles prominent; antennae thin, long, rufotestaceous, infuscated from fourth article. Mentum transverse and tumid, paramedial pits small and deep, median tooth simple, broad, length equal to epilobes of mentum.

Thorax. Pronotum convex, lateral margins arcuate, evenly rounded from apex to base, hind angles rounded, greatest width/length 1.5; base with welldefined margin from lateral impressions to the hind angles; medial impressed line complete and anterior transverse impressions complete, faint or interrupted medially (Fig. 15). Prosternal process smoothly rounded, without lateral margin.

Elytra parallel sided, widest at the middle, humeral angles moderately prominent, subapical sinuation shallow; striae complete, punctate basally, smooth in the apical third to half; intervals smooth, subconvex. Flight wings usually full and reflexed (Fig. 17). A single female was found to have re-

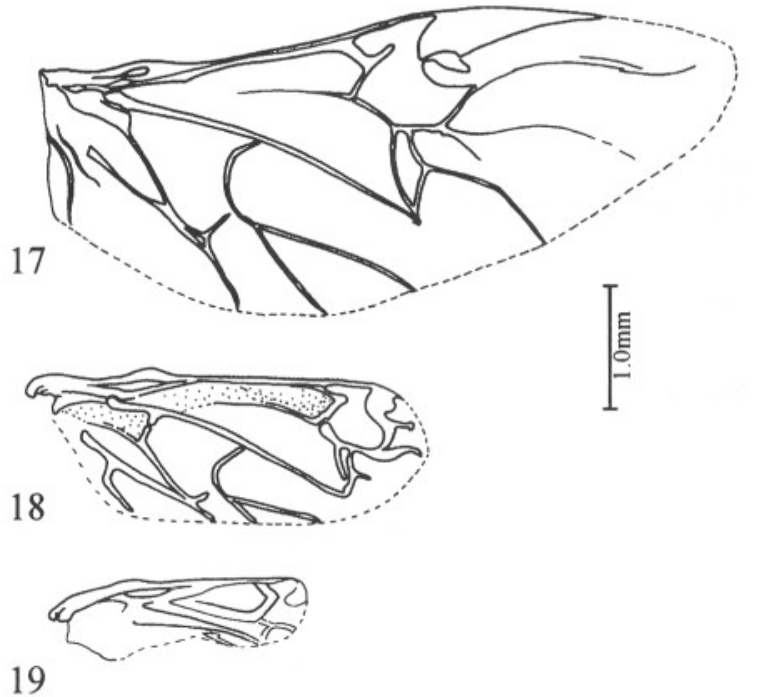

Figs. 17-19. Flight wings. Fig. 17. Full wing from Loxandrus straneoi sp.n. Fig. 18. Reduced wing from L. straneoi sp.n. Fig. 19. Reduced wing from $L$. icarus sp.n.

duced flight wings (Fig. 18). Legs robust; male profemur markedly swollen, metafemur sub-claviform, basally excavated to accommodate trochanter (Fig. 20 ), female with robust femora but not as clavate as in the male (Fig. 21); both sexes with mesotibiae arcuate (more strongly so in males); meso- and metatarsomeres 1-4 with poorly developed internal and well-defined external sulci, length of tarsomere 1 equal to tarsomere 5 , tarsomere 5 ventrally glabrous, male protarsi strongly asymmetrical. All thoracic sterna impunctate.

Abdomen. All visible ventrites impunctate, duller laterally and basally due to isodiametric microsculpture. Male median lobe (Figs. 1-3) with tip distinctly flexed dorsally and a slight asymmetrical depression ventrally (obsolete in some specimens), ostium dorsal, endophallus with dense fields of small spines at the base, a large, dense, crescent-shaped region of larger spines on the right lateral side, opening of the ejaculatory duct with completely sclerotized ring (Fig. 4). Female bursa copulatrix thick and highly convoluted (Fig. 24), asymmetrical, with common oviduct entering dorsally in a deep pocket; spermathecal gland duct connected to common oviduct at the base of the villous canal. No apparent spermatheca, accessory gland large; well-developed villous canal on surface of the common oviduct, middle third of canal smooth and lightly sclerotized; gonocoxite- 1 of ovipositor with 3 lanceolate setae near the apex, gono- 
coxite-2 triangular, stout, with 3-4 very small ensiform setae along the lateral margin (Fig. 26).

\section{Etymology}

The specific epithet of this species commemorates the taxonomic contributions made by Stefano Straneo to the knowledge of Loxandrus.

\section{Remarks}

Specimens were collected from the leaf litter in moist bottomland forest near the Noxubee and Pascagoula Rivers, and in adjacent areas that are subject to seasonal flooding and had extensive standing water. Loxandrus straneoi was collected together with $L$. taeneatus LeConte, L. velocipes Casey, L. brevicollis LeConte, L. robustus Allen, L. parallelus Casey, L. minor Chaudoir, Agonum striatopunctatum Dejean, A. punctiforme (Say), A. albicrus Dejean, and Olisthopus micans LeConte. Additionally, representatives of Chlaenius, Lophoglossus, and Oodes were also found at the same site.

Allen (1972: 165-7) presents a "hypothetical phylogeny" for Loxandrus species from North America. Using his characters and character state polarities, L. straneoi can be placed in a clade with $L$. velox (Dejean), L. aduncus Allen and L. agilis (Dejean) based on the following character states, 1) endophallus with gonopore ring fully sclerotized, 2) pronotum hind angles rounded, 3) abdominal segment II with ambulatory setae, 4) metasternum impunctate, and 5) modified median lobe. However, the presence of the strongly transverse mentum and paramedial pits in this species suggest a relationship with members of the clade including "ancestor 4" and all of its descendants (from L. celeris to L. fraus).

Loxandrus icarus, new species

(Figs. 5-8, 16, 19, 22, 23, 25, 27)

HOLOTYPE. đ̊, Va: Shenandoah Co., G. Washington N.F., Eliz. Furnace Cpgd., 6 June 1984, J.K.Liebherr, 700'el, deposited in CUIC: ALLOTYPE. + , same data as holotype. Deposited in CUIC: PARATYPES. CUIC $6 \delta^{\circ}, 1 \%, \mathrm{CMNH} 2 \delta^{\circ} \sigma^{\circ}$ KWWC $10^{\star}, \mathrm{MCZ} 1 \delta^{\circ}$ same data as holotype.

\section{Diagnosis}

Upper surface black, shiny, iridescent; pronotal border, legs and mouthparts paler, rufotestaceous; pro- notum convex, hind angles obtusely rounded, lateral margin with narrow bead, faint scattered punctures basomedially and in the basal impressions. Specimens key to couplet 49 in Allen's (1972) key. They can be separated from specimens of L. velox (Dejean) and subsequent species in the key by the distinct form of the median lobe and endophallus (Figs. $5-8$ ), and the strongly reduced flight wings (Fig. 19).

\section{Description}

Length from front margin of labrum to elytral apex 7.4-8.5 mm, maximum width across elytra 3.0-3.2 $\mathrm{mm}$; dorsal microsculpture consisting of strongly stretched sculpticells, faint and iridescent on pronotum and elytra, obsolete on head; ventral surface duller, microsculpture slightly stretched to nearly isodiametric mesh throughout, weaker medially.

Head short, eyes feebly convex, ocular ratio (width over eyes/width between eyes) 1.4-1.5; frontal sulci short, poorly developed or obsolete; mandibles prominent; antennae thin, long, rufotestaceous, fourth and more distal articles sometimes infuscated. Mentum weakly transverse, paramedial pits absent, median tooth simple, narrow and rounded as the apex, shorter than epilobes of mentum.

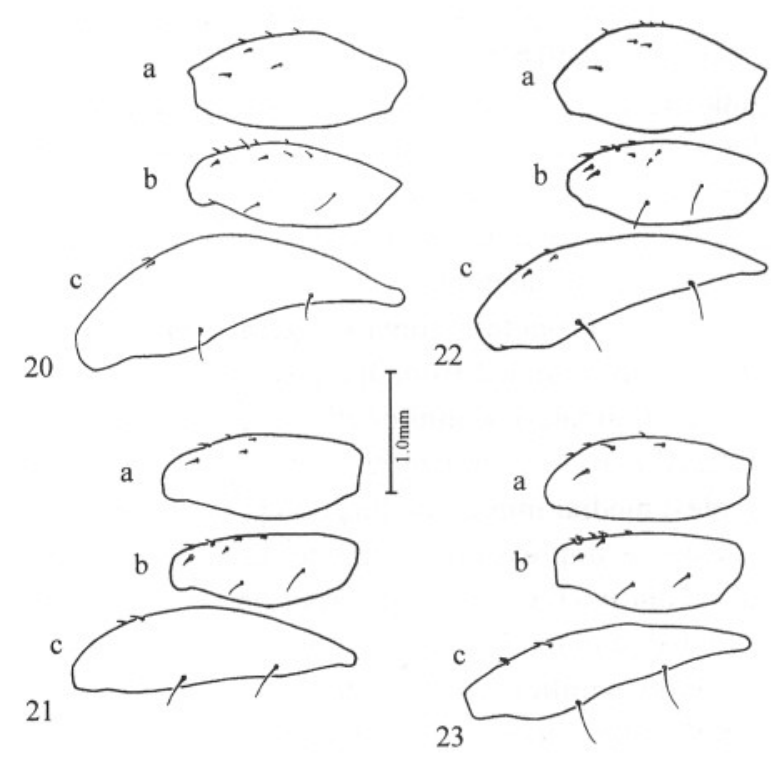

Figs. 20-23. Femora: Fig. 20. $\delta$ Loxandrus straneoi sp.n. Fig. 21. ㅇ L. straneoi sp.n. Fig. 22. o L. icarus sp.n. Fig. 23. + L. icarus sp.n. a. Profemur, b. Mesofemur, c. Metafemur. 
Thorax. Pronotum convex, elongate, lateral margins weakly arcuate, evenly rounded from apex to base, hind angles obtusely rounded, greatest width/ length 1.3; base with well-defined margin from lateral impressions to the hind angles; medial impressed line and anterior transverse impressions complete (Fig. 16). Prosternal process smoothly rounded, without lateral margin.

Elytra parallel-sided, widest at the middle, humeral angles moderately prominent, subapical sinuation shallow; striae complete, punctate basally, smooth in the apical third to half; intervals smooth, subconvex. Suture, apex and lateral margins paler. Flight wing reduced to small strap (Fig. 19), extending slightly less than half the length of the elytra. Metepisternum shorter than normal for genus, length of lateral edge/length of apical edge 1.3 for L. icarus (compare to 1.5 for $L$. rectus (Say), type species for the genus). Legs very robust; male profemur markedly swollen, meso- and metafemora noticeably expanded (Fig. 22), female with enlarged profemora but not as inflated as the male (Fig. 23); both sexes with mesotibiae arcuate (more strongly so in males); coxae and trochanters often darkly infuscated; mesoand metatarsomeres 1-4 with poorly developed external sulci, internal sulci absent, length of tarsomere 1 longer than tarsomere 5 , tarsomere 5 ventrally glabrous, male protarsi strongly asymmetrical. All thoracic sterna impunctate.

Abdomen. First visible ventrite lightly punctate in some individuals, other ventrites impunctate, duller laterally and basally from isodiametric microsculpture. Male median lobe (Figs. 5,6) with tip slightly reflexed ventrally, ostium dorsal. Endophallus with

24

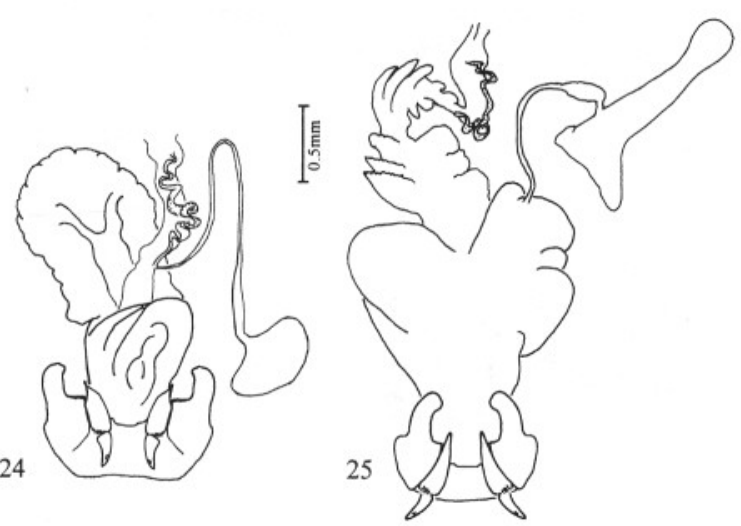

Figs. 24-25. Ventral view of female reproductive tract. Fig. 24. Loxandrus straneoi sp.n. Fig. 25. L. icarus sp.n. dense fields of small spines at the base, a large, elongate region of scattered spines on the right lateral side, a dense crescent-shaped field of spines on the left lateral side, and a small apical spine field (Figs. $7,8)$. The opening of the ejaculatory duct with completely sclerotized ring and an associated spine field. Female bursa copulatrix thick and highly convoluted; spermathecal gland duct directly connected to bursa wall, no apparent spermatheca, gland large; common oviduct enters the bursa apically, the oviduct between the bursa and the villous canal with a series of lobe-like pouches, villous canal well developed on surface of common oviduct (Fig. 25); gonocoxite-1 of ovipositor with 3-4 lanceolate setae near the apex, gonocoxite- 2 moderately curved with 3-4 very small ensiform setae along the margin (Fig. 27).

\section{Etymology}

The specific epithet refers to the reduced hind wing of this species and the lost wings of young Icarus, son of Daedalus, from Greek legend.

\section{Remarks}

The type specimens were collected running across decomposing leaf litter along a creek bottom at night. The immediate area had extensive standing water with a creek-bottom hardwood forest, bordered by sandy creek banks.

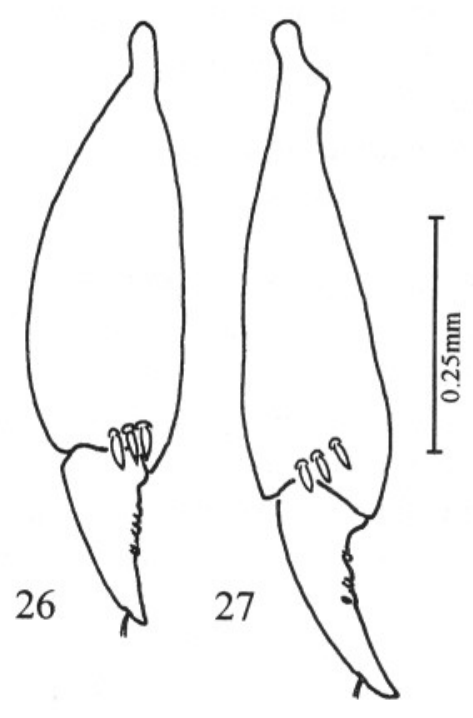

Figs. 26-27. Ventral view of right gonocoxite. Fig. 26. Loxandrus straneoi sp.n. Fig. 27. L. icarus sp.n. 
Other species collected together with $L$. icarus include L. velocipes Casey, L. vitiosus Allen, Agonum ferreum Haldeman, A. punctiforme (Say), A. fidele Casey, and A. aeruginosum Dejean. Additionally, representatives of Oodes, Chlaenius, Dicaelus and Galerita were also collected at the same site.

This species would fit Allen's (1972) "hypothetical phylogeny" for Loxandrus in or near the apical trichotomy that includes $L$. rossi Allen, $L$. minutus Allen, L. spinilunatus Allen and related species. Characters that support this relationship are: 1) endophallus with gonopore ring fully sclerotized 2 ) pronotum hind angles rounded 3) abdominal segment II with ambulatory setae, 4) metasternum impunctate and, 5) spinose field on the right lateral surface of endophallus.

Loxandrus quinarius, new species

(Fig. 28)

HOLOTYPE. $q$, Bolivia: Sta. Cruz., Ichilo, Buena Vista, 2 Oct 1994, 400 m. R.Ward, m.v.light. deposited $\mathrm{CMNH}$.

\section{Diagnosis}

Upper surface black, faintly shiny, not iridescent; legs and mouthparts paler, rufopiceous to rufotestaceous; pronotal base stringly bordered posterad laterobasal depressions, lateral margins subsinuate before hind angles, lateral margins widely reflexed from hind angles to basolateral setae, then narrowing to rounded front angles, base with scattered punctures, anterior transverse subapical impression complete. Eyes very prominent, greater than hemispherical (Fig. 28). Similar to L. strigomeroides Straneo and L. egae Straneo, species in Straneo's (1991) "group 5". Separated from all species in group five by the presence of punctures on the base of the pronotum. Loxandrus quinarius possesses distinctively reflexed pronotal lateral margins and strongly punctured elytral intervals, clearly distinguishing it from $L$. strigomeroides. The completely bordered prosternal process found in L. mirei Straneo is lacking in L. quinarius.

\section{Description}

Length from front margin of labrum to apex of elytra $8.3 \mathrm{~mm}$, maximum width across elytra $4.5 \mathrm{~mm}$; microsculpture isodiametric throughout, less developed on the head.
Head. Short, eyes strongly protuberant, ocular ratio (width over eyes/width between eyes) 1.8; frontal sulci well impressed, sharply delimited laterally, and shallowly delimited medially; mandibles prominent; antennae thin, long, rufopiceous. Mentum strongly transverse, tooth simple and small, length subequal to epilobes.

Thorax. Pronotum transverse, greatest width/length 1.5 ; sides with broadly reflexed border that narrows slightly in front of the anterolateral setae; hind angles about right; base with well defined margin from lateral impressions to the hind angles; disk convex; medial and anterior transverse impressions complete. Elytra subparallel, widest at the apical third, humeral angles moderately prominent, apical sinuation slight but apparent; striae complete and strongly punctured basally, smooth in the apical third; intervals smooth, subconvex. Flight wings apparently full, visible at elytral apices (not dissected). Metepimeron short, approaching the condition in the genus Adrimus Bates. Ventral surface with the same microreticulate surface throughout; mesepisternum, metepisternum coarsely punctate. Legs slender; pro- and metatibiae with internal and external carina, mesotibiae simple;

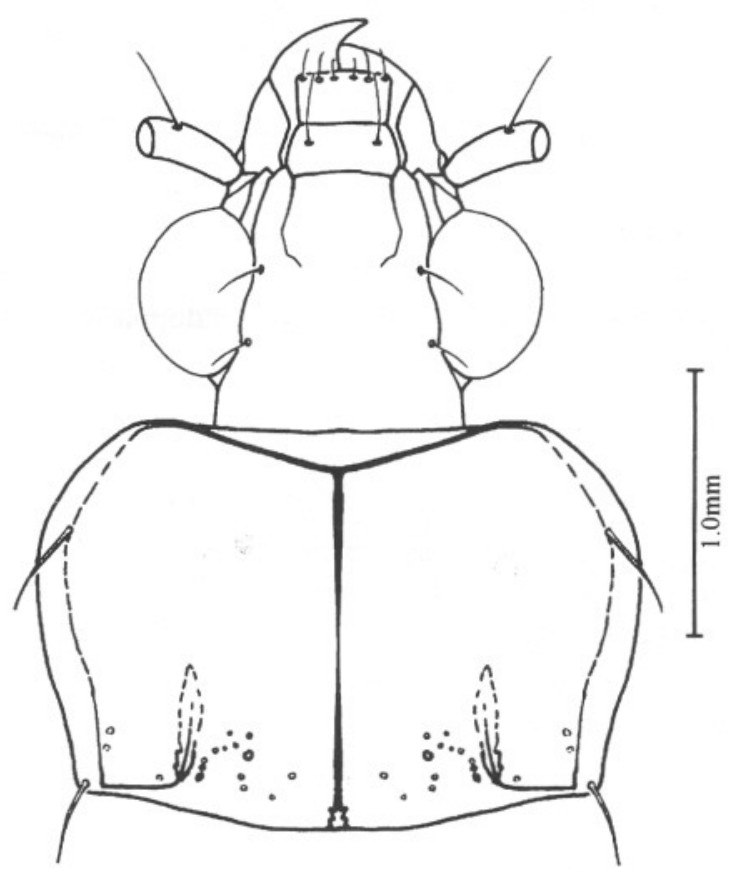

\section{8}

Fig. 28. Head and pronotum of Loxandrus quinarius sp.n. 
meso- and metatarsomeres 1-4 with internal and external sulci, tarsomere 1 longer than tarsomere 5, tarsomere 5 ventrally setose. Female protarsomere 1 with internal sulcus only.

Abdomen. Ventrites 1-2 laterally rugose to punctate. Males unknown; holotype female is the only known specimen and was not dissected.

\section{Etymology}

This species comprises the fifth species of Straneo's (1991) group five, a group of species that seem somewhat phenetically similar to each other. The name reflects this situation, recalling the failed quinarian classification of MacLeay (1821).

\section{Remarks}

This species is similar to L. strigomeroides, a species noted by Straneo (1991) as being "very unusual among Loxandrus...". The convex configuration of the eyes, and strongly margined base of the pronotum may prove to be synapomorphous for these taxa. However, any phylogenetic hypothesis will have to wait for more intensive sampling of characters and taxa analyzed cladistically. The narrow metepimeron in L. quinarius and other Loxandrus species suggests that, as presently conceived, Adrimus and Loxandrus may not reflect natural taxonomic groups.

\section{Additional records for Loxandrus species}

\section{Loxandrus strigomeroides Straneo, 1991}

(Figs. 9-12)

NEW COUNTRY RECORD: Bolivia, Buena Vista, Dep. Sta. Cruz, 1922, R.C.Robert. USNM (1 $\left.{ }^{\star}\right)$.

This species was described and illustrated by Straneo (1991). Three males are known from the type series. The original type series was collected in Venezuela. Two of the males were too teneral for dissection and the single dissected male had a broken median lobe. Based on the Bolivian material, the median lobe (Figs. 9-10) is simple and straight, the ostium deflected to the right. The endophallus has six distinct spine fields (Figs. 11-12). This new record extends the known range across the Amazon basin, with the Bolivian specimen conforming in all respects to the original species description.

\section{Loxandrus mirei Straneo, 1991}

(Figs. 13-14)

ADDITIONAL RECORDS: Bolivia, Santa Cruz, Ichilo Province, Buena Vista, 400m, 3 Oct 1994, R. Ward, mercury vapor light. $2 \delta$ o, $1+\mathrm{CMNH}$.

This species was described from a single female. These three additional specimens were collected at the type locality. The median lobe is strongly curved with the ostium dorsal (Fig. 13). The endophallus has a uniform covering of small spines at the base, two large tooth-like spines dorsolaterally and a distinct dorsal spinose field (Fig. 14). The external morphology of these specimens conforms to the original species description in all respects.

\section{New synonymy}

Loxandrus velocipes Casey 1918:390.

Loxandrus inferus Allen 1972:137 (NEW SYNONYMY)

Allen (1972: 137-8) described L. inferus Allen and compared it to $L$. velocipes stating that "They $[L$. inferus and $L$. velocipes] appear to be alike in all external characters and can be separated only on the basis of characters associated with the male genitalia." He detected only one difference, presence or absence of the right lateral scale group of the endophallus. Specimens from throughout the range of these forms dissected in the course of this study have a right lateral scale group with from zero to 20 spines, showing complete gradation between the two named forms.

\section{ACKNOWLEDGMENTS}

We thank Robert Davidson, Carnegie Museum of Natural History and T. Erwin and G. House, Smithsonian Institution, Washington D.C. for providing loans of material; and R. Brown, Mississippi State University for his hospitality to the CU entomology students during the $1997 \mathrm{col}-$ lecting trip to Mississippi.

\section{REFERENCES}

ALLEN T (1972) A revision of the genus Loxandrus LeConte (Coleoptera: Carabidae) in North America. Entomologica Americana 46: 1-184 
ALLEN T, BALL G E (1980) Synopsis of Mexican taxa of the Loxandrus series (Coleoptera: Carabidae: Pterostichini). Transactions of the American Entomological Society $105: 481-576$

BOUSQUET Y, LAROCHELLE A (1993) Catalogue of the geodephaga (Coleoptera: Trachypachidae, Rhysodidae, Carabidae including Cicindelini) of America north of Mexico. Memoirs of the Entomological Society of Canada 167: $397 \mathrm{pp}$

DARLINGTON J P JR (1962) The carabid beetles of New Guinea part I. Cicindelinae, Carabinae, Harpalinae through Pterostichini. Bulletin of the Museum of Comparative Zoology 126: 323-564

CASEY T L (1913) Memoirs on the Coleoptera. IV. Lancaster, PA, The New Era Printing Co

LIEBHERR J K, WILL K W (In press) Inferring relationships within Carabidae (Insecta, Coleoptera) from characters of the Female Reproductive Tract. dal Bollettino del Museo Regionale di Scienze Naturali - Torino

LINDROTH C (1969) "The Ground Beetles (Carabidae, excl. Cicindelae) of Canada and Alaska." Opusc Ent Part 1: xlviii.

MACLEAY W S (1821) Horae Entomologicae: or Essays on the Annulose Animals, Vol. I, Part II. Containing an attempt to ascertain the rank and situation which the celebrated insect Scarabeaus sacer, holds among organized beings. S.Bagster, London

MOORE B P (1965) Studies on Australian Carabidae. 4The Pterostichinae. Transactions of the Royal Entomological Society of London 117: 1-32

MOORE B P (1979) Chemical defense in Carabids and its bearing on phylogeny. pp 193-203. In ERWIN T L, BALL G E, WHITEHEAD D R, HALPERN A L (Eds), Carabid beetles: their evolution, natural history, and classification. The Hague, Junk $635 \mathrm{pp}$

MOORE B P, WALLBANK B E (1968) Chemical composition of the defensive secretions in carabid beetles and its importance as a taxonomic character. Proceedings of the Royal Entomological Society of London, series B, Taxonomy 37: 62-72

NIXON K C, WHEELER Q (1990) An amplification of the phylogenetic species concept. Cladistics 6: 211223

STRANEO S (1979) Notes about classification of South American Pterostichini with a key for determination of subtribes, genera and subgenera (Coleoptera: Carabidae). Quaestiones Entomologicae 15: 345-356

STRANEO S (1991) South American species of Loxandrus LeConte, 1852 (Coleoptera: Carabidae: Pterostichini. Annals of Carnegie Museum 60: 1-62 